\title{
Parameters for Thermal Energy Systems Resilience
}

\author{
Alexander M. Zhivov, Ph.D. ${ }^{1 *}$ \\ ${ }^{1}$ US Army Engineer R\&D Center, Champaign, IL (USA)
}

\begin{abstract}
To provide a building design that is robust, adaptable, and affordable, one must understand the aspects of the building's geographic location that will impact equipment selections, operating hours, and maintenance needs. One must also consider the building's "thermal resilience," i.e., its ability to withstand a heating plant outage. Designing for resilience is of growing importance, especially for military and government installations that must maintain critical functions even during outages. Buildings with a fast rate of temperature degradation with the loss of heating system function have low resiliency; buildings with a slower rate of temperature degradation have higher resiliency. In extreme cold climates, resiliency can play an integral role in protecting property during an outage. A drop in indoor temperature can pose a risk of freezing plumbing, which can lead to burst pipes and interior flooding that can cause enormous and costly damage, and which can effect a loss of workspace in an office building. More resilient designs must consider not only building HVAC installations, but also building envelope and the whole energy infrastructure, including thermal capacity of concrete and brick walls, internal water pipes, critical system redundancy, outside insulation without weak points, and a centrally controlled, low carbon hot water heat supply. This paper describes a quantitative approach to evaluate a system's resiliency based on analytical and experimental studies conducted under IEA EBC Annex 73 and the Environmental Security Technology Certification Program (ESTCP) project Technologies Integration to Achieve Resilient, Low-Energy Military Installations, to evaluate building energy performance in extreme climate conditions. This work recommends that more thermally resilient designs for buildings in cold climates include consideration of increased thermal resistance of the building envelope, improved whole-building airtightness, and higher thermal mass.
\end{abstract}

\section{Introduction}

Designing a building for "thermal resilience," i.e., its ability to withstand a heating plant outage is of growing importance. Buildings with a relatively low rate of temperature degradation with the loss of heating system function have a greater resiliency than those with higher rates of temperature degradation. Metrics for energy resilience fall into two broad categories: attribute based, and performance based (Vugrin et al. 2017 [1]; Roege et al. 2014 [2]). Attribute-based metrics can be counted or populated via checklists or surveys. They often describe the characteristics that make a system resilient, such as robustness or reliability (NIAC 2009 [3]). However, these metrics are difficult to integrate into the Energy Master Planning process because they are not easily compared with performance-based metrics in other categories, such as cost-effectiveness (e.g., overall net present value of the energy system) or sustainability (e.g., kilograms of carbon dioxide equivalent emissions) (Jeffers et al. 2020 [4]).

This paper provides a definition of resilience metrics and offers a methodology to address site-specific requirements for resilience with the emphasis on resilience of thermal energy systems. More detailed discussion of this topic can be found in (Zhivov et. al $2021[5])$.

\footnotetext{
*Corresponding author: Alexander.M.Zhivov@usace.army.mil
}

For some critical missions where any amount of interruption from an event is unacceptable, it is assumed that power quality requirements and a short-term uninterruptable power supply to mission critical equipment is handled using building-level energy systems. Other critical missions can withstand small disruptions as long as the system can recover quickly. This can be quantified as a deviation in mission availability from baseline operations to the degraded system state following a disturbance. A quantitative approach to resilience of energy system, supplying energy to the building can include (but is not limited to) the following metrics:

- Energy System Robustness

- Energy System Recovery time

- Energy Availability

- Energy Quality.

The first three parameters are critical in the selection of the energy supply system architecture and of the technologies that comprise the system, and in satisfying requirements related to energy system resilience. As described by Zhivov et al. [5], requirements to Energy Availability and Energy System Recovery Time depend on:

- Criticality of the mission served by the system,

- System repairability, which has significant dependence on remoteness of the facility hosting the mission, and 
- Redundancy of facilities that can serve the same critical function.

Energy Robustness requirements depend on the value of the mission critical load; they (1) can be measured as the percentage of the load that is available to the mission in degraded state from the total mission essential load requirements (Figure 1), and (2) can also be related to the overall building energy load under normal (Blue Sky) conditions.

Energy Quality is another important quantitative metric for the energy system serving critical functions. Energy quality should be considered as a design parameter for internal building energy systems. Most of the mission-specific energy quality requirements can be handled by the building-level energy systems. Buildinglevel electric systems (nano-grids) generally include redundant or backup components and infrastructure for power supply, uninterruptible power supply (UPS), automatic transfer switches, data communications connections, environmental controls (e.g., airconditioning, fire suppression) and various security devices. These electrical systems can be designed to provide power with a severe demand on the stability and level of the frequency, voltage, and waveform characteristics of the uninterruptable electrical power to mission critical equipment and can operate in an islanded mode for a period between 15 minutes and several hours.

For resilient thermal energy system planning, a wellinsulated, airtight building envelope of a massive building can maintain a habitable indoor air temperature for several hours after heat or cooling supply to the building is interrupted (see Zhivov et al. [6] for more details).

These internal electrical and thermal systems are designed based on the class or tier of such facilities. Requirements for Energy Availability, Energy Recovery Time, and Energy Quality to be specified for energy systems that provide energy to the building will therefore be different from those required by critical equipment and personnel.

Energy Robustness is defined as "the ability to absorb shocks and continue operating" (NERC 2018 [7]). For many critical facilities, there may be many mission assets that are considered uninterruptible, critical but interruptible, and life and safety related. Since it is imperative to the mission that these assets remain online, any undelivered load to such facilities or assets would be considered mission failure, i.e., the shock will have caused failure. Energy Robustness is a metric that shows the power availability, $\mathrm{P}$ (in $\mathrm{kW}$ and/or $\mathrm{kBtu} / \mathrm{hr}$ ) to satisfy critical mission loads over a period of time immediately following the event, measured as a fraction of the mission critical requirement or a fraction of the Baseline energy requirement.

\section{Method}

\subsection{Energy robustness metric}

Using the Energy Robustness metric, we can quantify the overall resilience of a system in two phases: absorption of the event, and recovery. Consider an event occurring as shown in Figure 1. Immediately following the event, there is a sharp drop in the load available to mission. For electric energy systems, the duration of phase one is much shorter than for thermal energy systems, unless thermal systems are used for processes using steam or hot water. This change from the baseline to the degraded state represents the robustness of the system to that particular event. The time required to restore the system to its baseline state is referred to as recovery. The smaller the change in load available to mission and the shorter the recovery time, the more robust the system.

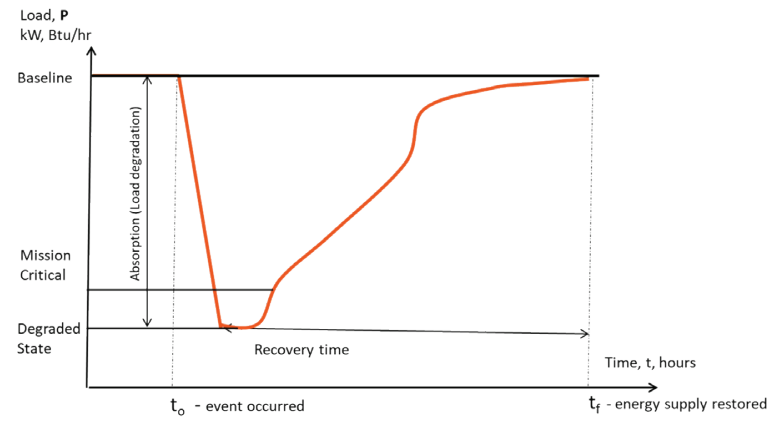

Figure 1. System Response to a disruptive event.

The robustness, $\mathrm{R}$ of the system to any particular event can be quantified using Equations 1 and 2. The smaller the area between the baseline and the curve, the more resilient the system. Robustness will be measured on the scale between 0 and 1, where 1 indicates the most resilient system:

$$
\begin{aligned}
R_{\text {m.c. }} & =\frac{E_{\text {event }}}{E_{m . c .}} \\
R_{\text {baseline }} & =\frac{E_{\text {event }}}{E_{\text {baseline }}}
\end{aligned}
$$

where $R_{\text {m.c. }}$ and $R$ baseline are system robustness measured against the mission critical load and the baseline load; $\mathrm{E}_{\text {event }}, \mathrm{E}_{\mathrm{m} \text {.c. }}$, and $\mathrm{E}_{\text {event }}$ are energy supplied to the building during the period of time between $t_{o}$ and $t_{f}$ with the baseline load, mission critical load and degraded due to event load and can be illustrated by the area between the line showing the baseline mission availability and the curve representing the actual mission performance over time:

$$
E=\int_{t_{o}}^{t_{f}} P(t) d t
$$

Depending on mission needs, it may be more important to prioritize either absorption or recovery. For example, Figure 2 shows two systems with different levels of absorption. The two systems have the same recovery time, but System 2 has a lower initial decrease in power available to the building. System 2 is more resistant to the postulated event and is more robust than System 1 despite having the same recovery time. 


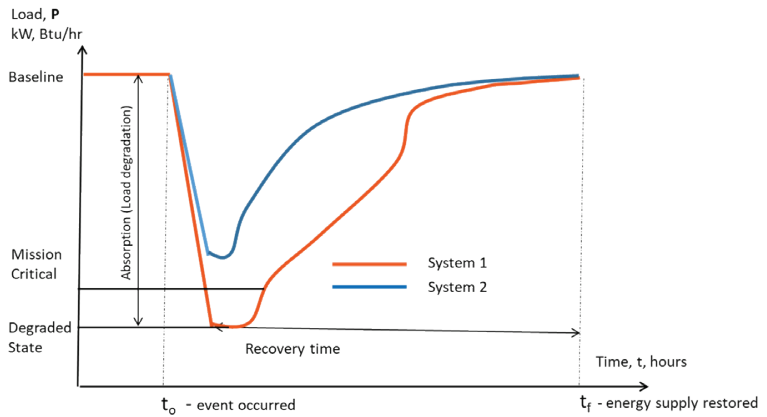

Figure 2. Two systems with different absorption.

In other cases, it may be more important to prioritize recovery from an event as opposed to absorption. Figure 3 shows two systems with similar absorption to an event, but different recovery times. Though both systems have the same ability to absorb the shock from the event, the shorter recovery time for System 2 yields larger area under the curve. Accordingly, System 2 can be said to be more resilient than System 1.

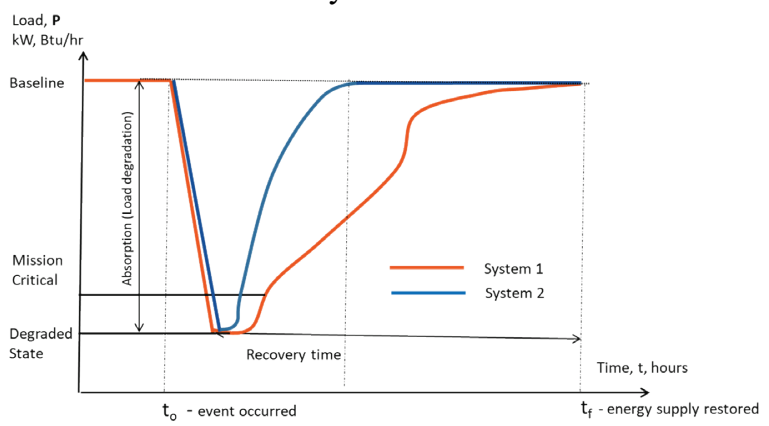

Figure 3. Two systems with different recovery time.

In the recovery phase, the system is stabilized, and no further damage or degradation is expected. The system may be operating in alternate or emergency modes with a reduced load. At the beginning of this phase energy may be provided to critical systems using internal building system with the power storage capacity followed by standby generators, emergency boilers, alternate utility feeds, or distributed energy resources. In this phase, the emphasis is on restoring the system to its baseline operation.

As previously discussed, the shorter the recovery time, the more robust the system. Recovery time is determined by the average length of time required to return damaged components to service. In general, the availability of energy for the mission increases as assets are recovered. For large or complex systems, availability during the recovery phase may change continuously. For smaller systems, or where fewer redundant paths exist, it can be more useful to consider the change in availability during the recovery phase as a step function. That is, there are discrete step changes in availability as components or success paths are returned to service.

Figure 4 provides an example of this concept for an electric energy system. In this example, an event has disabled both the onsite generation as well as one of two redundant utility feeders resulting in a significantly reduced power supply to the mission (degraded state).
The onsite generators are quickly returned to service, resulting in a large step increase in availability to support mission critical loads. During generator unavailability, power to mission critical assets is provided by UPSs integrated into the nano-grid. After some time, the redundant utility feed is returned to service, resulting in a second step increase in availability. It is important to note that for a single success path to be restored, all series components must be fully restored before improvements in availability are realized. For example, if an event disables a backup generator, its associated fuel tank, and fuel lines, all of these assets must be repaired before that feed is considered back online.

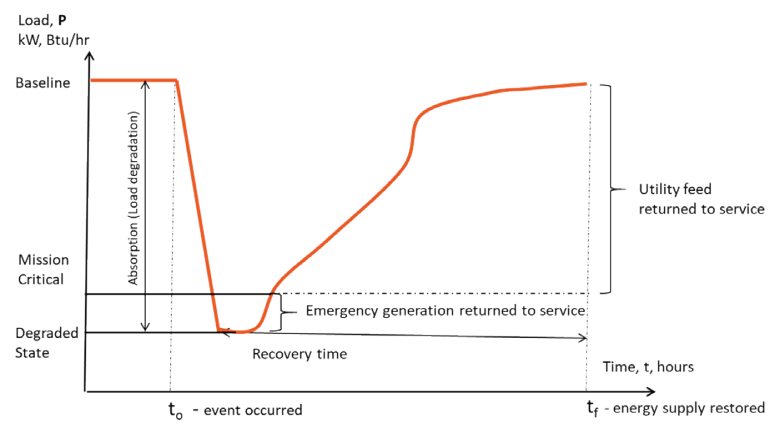

Figure 4. Stepped recovery of power system assets.

If one considers the step-change model illustrated in Figure 4, it becomes apparent that the recovery time for the system can be approximated using the mean time to repair (MTTR) for the various affected components. However, designers, planners, and facility managers must use caution when using MTTR to anticipate recovery time following a contingency event. MTTR data is typically based on failure modes that occur during normal operation. Contingency events may cause different failures to occur, and additional logistics delays must be considered based on the nature of the event and the location of the site. To determine the recovery time for a system, MTTR data should be used as an input to an evaluation of the disaster recovery plan.

\subsection{Maximum allowable downtime}

Following a contingency event, the facility or site should have a plan in place to adapt to and recover quickly from the effects of the event. Due to limitations of personnel, resources, and logistics, repairs for all components cannot occur simultaneously. Some assets may need to be restored in sequence. The priority shall be given to restoring power to the level that satisfies the needs of mission critical loads. In this case, the maximum time to repair (MaxTTR) of the system providing mission critical load shall be smaller than maximum allowable downtime assigned based on the configuration and a storage capacity of nano-grid.

While there have been more discussions and research related to resilience of electric energy systems, resilience of thermal energy systems is especially important for extreme climate locations. Resilience requirements to a thermal system comprised of energy conversion, distribution, and storage components 
depends on thermal parameters necessary to one or several of the following purposes:

- $\quad$ perform the required work in a building in a safe and efficient manner (habitability),

- $\quad$ support processes housed in the building, and

- provide conditions required for a long-term "health" of the building itself (sustainability).

Maximum time to repair of thermal systems serving a building can be defined in terms of how long the process can be maintained or the building remains habitable or protected against damage to water pipes, sewer, fire suppression systems, sensitive content, or mold damage during extended loss of energy supply from extreme weather events. The analysis presented in Liesen et al. [8] shows that major factors affecting the time when the internal temperature reaches the threshold of building habitability or sustainability include:

- difference between indoor and outdoor air temperature

- building envelope airtightness

- building envelope insulation properties, including insulation levels of its components, and thermal bridging

- internal thermal load (people and appliances/equipment connected to electric power).

\subsection{Thermal mass}

Also, the thermal mass of building structures composed of concrete, masonry, or stone materials that constitute high levels of embodied energy enables the building to absorb and store heat to provide "inertia" against temperature fluctuation and allows an increase in time allowed for the thermal system to be repaired. Figure 5 shows how these factors will influence the time of building temperature degradation from the comfortable level $\left(t_{0}\right)$ to the habitability $\left(t_{h}\right)$ and sustainability $\left(t_{s}\right)$ temperature thresholds.

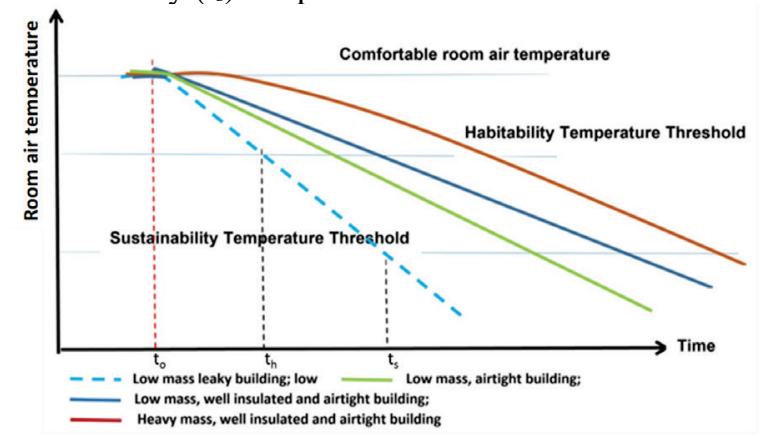

Figure 5. Notional example of temperature decay rate for different types of building envelope: comfortable level (to), habitability (th) and sustainability (ts) temperature thresholds.

Usually, national requirements for building envelope characteristics, e.g., thermal insulation values of its components, building envelope air tightness, vapor permeability, building mass, detailing, etc., are based on economic and environmental considerations. Thermal energy system resilience consideration brings another dimension to the optimization process of these parameters.

\section{Recommendations}

Increased thermal insulation, improved thermal bridge detailing, and whole-building airtightness all have a significant potential to impact the thermal resiliency of buildings in cold climates. In a study of the effect of different levels of building envelope energy efficiency (e.g., thermal insulation, air tightness) and mass, an indoor air temperature decay study was conducted to simulate interruption of the mechanical heating supply during outside temperature conditions of $-40^{\circ} \mathrm{F}\left(-40^{\circ} \mathrm{C}\right)$. [8] This study found that a building with a mass structure (concrete masonry unit [CMU], poured slab) and a less energy efficient building envelope design, the indoor air temperature approached the habitability level of $60^{\circ} \mathrm{F}\left(16^{\circ} \mathrm{C}\right) 9$ hours faster than for a similar building with a more energy efficient building envelope, and 3 hours faster for the similar arrangements with a framed (i.e., lower thermal mass) building structure.[8] Intersection of the indoor air temperature decay line with the building sustainability threshold of $40^{\circ} \mathrm{F}\left(4^{\circ} \mathrm{C}\right)$ occurs 27 hours and 10 hours faster respectively for the same scenarios. The difference in MaxTTR calculated for mass highperformance buildings and frame buildings built using pre-1980 code is much more significant. Figure 6 shows these results; Table 1 lists input parameters associated with the different building architypes and the corresponding results.

\section{Results}

Based on these findings, it is evident that a more energy efficient building envelope and a higher thermal mass structure improves thermal resiliency, and an exterior temperature of $-40^{\circ} \mathrm{F} \quad\left(-40^{\circ} \mathrm{C}\right)$, allows approximately 8 more habitable hours and 33 more sustainable hours during which the heating system can be repaired. Therefore, more thermally resilient designs for buildings in cold climates should include consideration of increased thermal resistance of the building envelope, improved whole-building airtightness, and higher thermal mass.

Airtightness of $0.15 \mathrm{cfm} / \mathrm{ft}^{2}\left(0.75 \mathrm{~L} / \mathrm{s} . \mathrm{m}^{2}\right)$ at $75 \mathrm{~Pa}$ in cold climates is achievable; this level of airtightness results in significant energy use reduction and improved energy resilience of buildings. To realize this level of airtightness, special consideration should be given to air barrier details at the roof/wall joints.

More detailed recommendations are summarized in the Guide for Resilient Thermal Energy Systems Design for Cold and Arctic Climates [9] 


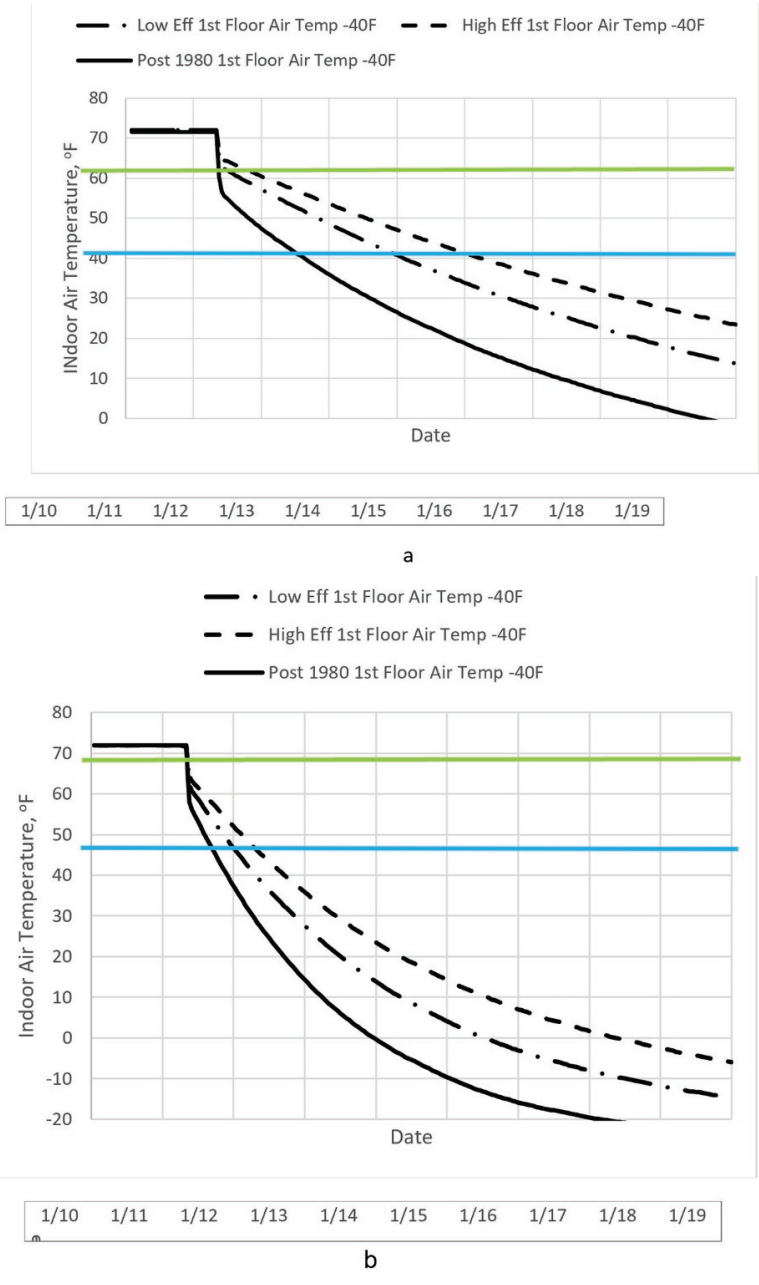

Figure 6. Indoor air temperature decay in a high efficiency building vs. a lower efficiency building when heat supply is interrupted at outside air temperature $-40^{\circ} \mathrm{F}\left(-40^{\circ} \mathrm{C}\right)$ :

(a) thermally massive building, (b) framed building.

Table 1. Building envelope characteristics for mass and frame buildings located in cold and Arctic climates used for study of interior temperature decay when heating is interrupted.

\begin{tabular}{|c|c|c|c|c|c|c|}
\hline \multirow[b]{2}{*}{$\begin{array}{c}\text { Building } \\
\text { Parameters }\end{array}$} & \multicolumn{3}{|c|}{ Mass Building } & \multicolumn{3}{|c|}{ Frame Building } \\
\hline & Pre-1980 & $\begin{array}{c}\text { Low } \\
\text { Efficienc }\end{array}$ & $\begin{array}{c}\text { High } \\
\text { Efficiency }\end{array}$ & $\begin{array}{l}\text { Pre- } \\
1980\end{array}$ & $\begin{array}{c}\text { Low } \\
\text { Efficiency }\end{array}$ & \begin{tabular}{|c|} 
High \\
Efficiency
\end{tabular} \\
\hline $\begin{array}{l}\text { Walls R-value, } \\
{ }^{\circ} \mathrm{F} \cdot \mathrm{ft}^{2} \cdot \mathrm{hr} / \mathrm{Btu} \\
\left(\left[\mathrm{m}^{2} \cdot \mathrm{K}\right] / \mathrm{W}\right)\end{array}$ & $\begin{array}{l}20.5 \\
(3.6)\end{array}$ & $40(7.0)$ & $50(8.8)$ & $\begin{array}{l}20.5 \\
(3.6)\end{array}$ & $40(7.0)$ & $50(8.8)$ \\
\hline $\begin{array}{l}\text { Roof R-value, } \\
{ }^{\circ} \mathrm{F} \cdot \mathrm{ft}^{2} \cdot \mathrm{hr} / \mathrm{Btu}, \\
{ }^{\circ} \mathrm{F} \cdot \mathrm{ft}^{2} \cdot \mathrm{hr} / \mathrm{Btu} \\
\left(\left[\mathrm{m}^{2} \cdot \mathrm{K}\right] / \mathrm{W}\right) \\
\end{array}$ & $\begin{array}{l}31.5 \\
(5.5)\end{array}$ & $45(7.9)$ & $60(10.6)$ & $\begin{array}{l}31.5 \\
(5.5)\end{array}$ & $45(7.9)$ & $60(10.6)$ \\
\hline $\begin{array}{c}\text { Air Leakage, } \\
\text { cfm } / \mathrm{ft}^{2} \text { at } 0.3 \\
\text { in. w.g. }\left(\mathrm{L} / \mathrm{s} \cdot \mathrm{m}^{2}\right. \\
\text { (@75) }\end{array}$ & $0.4(2)$ & $\begin{array}{c}0.25 \\
(1.25)\end{array}$ & $\begin{array}{c}0.15 \\
(0.75)\end{array}$ & $0.4(2)$ & $\begin{array}{c}0.25 \\
(1.25)\end{array}$ & $\begin{array}{c}0.15 \\
(0.75)\end{array}$ \\
\hline $\begin{array}{c}\text { Window (R- } \\
\text { value, } \\
{ }^{\circ} \mathrm{F} \mathrm{ft}^{2} \cdot \mathrm{hr} / \mathrm{Btu}, \mathrm{U} \\
\text { value, } \\
\mathrm{W} /\left(\mathrm{m}^{2} \cdot \mathrm{K}\right) \\
\end{array}$ & $\begin{array}{c}\text { Double } \\
\text { Pane; } \\
\mathrm{R}=1.78 \\
/ \\
\mathrm{U}=0.56\end{array}$ & $\begin{array}{c}\text { Double } \\
\text { Pane; } \\
R=3.34 \\
U=0.3\end{array}$ & $\begin{array}{c}\text { Triple } \\
\text { Pane; } \\
\mathrm{R}=5.25 / \\
\mathrm{U}=0.19 \\
\end{array}$ & $\begin{array}{c}\text { Double } \\
\text { Pane; } \\
\mathrm{R}=1.78 \\
/ \\
\mathrm{U}=0.56\end{array}$ & $\begin{array}{c}\text { Double } \\
\text { Pane; } \mathrm{R}= \\
3.34 / \\
\mathrm{U}=0.3\end{array}$ & \begin{tabular}{|c|} 
Triple \\
Pane; \\
$\mathrm{R}=5.25 /$ \\
$\mathrm{U}=0.19$
\end{tabular} \\
\hline
\end{tabular}

\begin{tabular}{|c|c|c|c|c|c|c|}
\hline \multirow{3}{*}{$\begin{array}{c}\text { Building } \\
\text { Parameters }\end{array}$} & \multicolumn{3}{|c|}{ Mass Building } & \multicolumn{3}{c|}{ Frame Building } \\
\cline { 2 - 7 } & Pre-1980 & $\begin{array}{c}\text { Low } \\
\text { Efficiency }\end{array}$ & $\begin{array}{c}\text { High } \\
\text { Efficiency }\end{array}$ & $\begin{array}{c}\text { Pre- } \\
\mathbf{1 9 8 0}\end{array}$ & $\begin{array}{c}\text { Low } \\
\text { Efficiency }\end{array}$ & $\begin{array}{c}\text { Efigh } \\
\text { Efficiency }\end{array}$ \\
\hline $\begin{array}{c}\text { MTTR } \\
\text { Habitability } \\
\left(60^{\circ} \mathrm{F}\left[16^{\circ} \mathrm{C}\right]\right.\end{array}$ & 1 hour & 3 hours & 10 hours & $<1$ hour & 2 hours & 4 hour \\
\hline $\begin{array}{c}\text { MTTR } \\
\text { Sustainability } \\
\left(40^{\circ} \mathrm{F}\left[4^{\circ} \mathrm{C}\right]\right)\end{array}$ & 20 hours & 36 hours & 51 hours & 10 hours & 18 hours & 24 hours \\
\hline
\end{tabular}

\section{References}

[1] Vugrin, E., A. Castillo, and C. Silva-Monroy. 2017. Resilience metrics for the electric power system: A performance-based approach. Sandia National Laboratories. Report SAND2017-1493. Albuquerque, NM: Sandia National Laboratories.

[2] Roege, P., Z.A. Collier, J. Mancillas, J.A. McDonagh, and I. Linkov. 2014. Metrics for energy resilience. Energy Policy 72:249-56.

[3] NIAC. 2009. Critical infrastructure resilience: Final report and recommendations. National Infrastructure Advisory Council. Washington, DC: Secretary of the Department of Homeland Security.

[4] Jeffers, R.F., A.M. Wachtel, A.M. Zhivov, C.B. Thompson, A. Srivastava, and P.W. Daniels. 2020. Integration of resilience goals into energy master planning framework for communities." ASHRAE Transactions 126. Part 1.

[5] A. Zhivov, A. Stringer, M. Fox, J. Benefiel, P. Daniels, and T. Tarver, "Defining, measuring and assigning resilience requirements to electric and thermal energy systems," ASHRAE Trans., vol 127, Part. 1, 2021a.

[6] A. Zhivov, W. Rose, R. Patenaude, and W. Warren, "Requirements for building thermal conditions under normal and emergency operations in extreme climates," ASHRAE Trans., vol. 127, Part. 1, $2021 b$.

[7] NERC. 2018. Reliability issues steering committee report on resilience. Atlanta: North American Electricity Reliability Council. https:/www.nerc.com/comm/RISC/Related $\% 20$ Files $\% 20$ DL/RISC\%20Resilience\%20Report_Approved_RISC_Committee_November_8_2018_Board_Accepted.pdf.

[8] R. Liesen, B. Morton, and B. Diggs-McGee, "Thermal energy system resilience: Thermal decay test (TDT) in cold/arctic climates, part II modeling," ASHRAE Trans., vol. 127, Part. 2, 2021.

[9] Guide for Resilient Thermal Energy Systems Design for Cold and Arctic Climates. Editor : Alexander Zhivov. US Army Engineer Research and Development Center. Champaign, IL. 